\title{
Translational Science, DNA Commercialization, and Informed Consent: The Need for Specific Terminology, Insights from a Review of H3Africa Projects
}

\author{
Patricia Marshall $^{a}$ Charmaine D.M. Royal $^{b}$ Ruth Chadwick ${ }^{c}$ \\ aDepartment of Bioethics, Case Western Reserve University, Cleveland, OH, USA; ${ }^{b}$ African \& African American \\ Studies, Biology, Global Health, and Family Medicine \& Community Health, Duke University, Durham, NC, USA; \\ 'School of Social Sciences, Cardiff University, Cardiff, UK
}

\section{Keywords}

Ethics of genetic research - DNA commercialization . Informed consent $\cdot \mathrm{H} 3 \mathrm{Africa} \cdot$ Commercialization Typology

\begin{abstract}
In the past decade, there has been an acceleration in genomic research, its applications, and its translation into healthcare products and services for the benefit of public health. These advances are critical to realizing the potential of genomic research for facilitating improved health and disease prevention, diagnosis, and treatment. Despite its tremendous opportunities, the dynamic and increasingly global landscape of genomic research commercialization has been accompanied by a variety of ethical challenges and concerns. The potential for unauthorized use of DNA samples from African people to develop a DNA chip amplifies discussion on the meanings, implications, and impacts of commercialization, benefit sharing, and appropriate consent in genomic research. Leadership of the Human Heredity and Health in Africa (H3Africa) Consortium convened a panel of experts to review research ethics practices employed in H3Africa Consortium projects and make recommendations regarding commercialization. Eighteen investigators submitted documents for projects involving data sharing and
\end{abstract}

karger@karger.com www.karger.com/phg

Karger"

GOPEN ACCESS
(C) 2022 The Author(s)

Published by S. Karger AG, Basel

This is an Open Access article licensed under the Creative Commons Attribution-NonCommercial-4.0 International License (CC BY-NC) (http://www.karger.com/Services/OpenAccessLicense), applicable to the online version of the article only. Usage and distribution for commercial purposes requires written permission. use of genetic information. A total of 39 informed consent documents associated with the 18 projects were reviewed. All 18 projects specified that samples would be used in future research. Less than half of the projects included language noting that samples could be used in drug or product development, that DNA samples would not be sold, and that profits would not be shared with participants. Four projects referred to commercialization. Analysis of information included in consent documents contributed to the development of a Commercialization Typology. The Typology identifies factors to consider regarding acceptability of particular instances of commercialization. DNA samples for translational research in product development require a transparent commercialization framework to inform the consent process.

(C) 2022 The Author(s) Published by S. Karger AG, Basel

\section{Introduction}

Over the past decade, there has been an acceleration in genomic research, its applications, and its translation into healthcare products and services for the benefit of public health. These advances are critical to realizing the potential of genomic research for facilitating improved health 
and disease prevention, diagnosis, and treatment. DNA microarray chips, which contain thousands of DNA sequences, increase researchers' capacity to identify gene sequences associated with particular diseases and to develop pharmaceuticals. The creation of DNA chips require samples from large numbers of individuals and populations. An important goal of scientists is to expand representation of diverse populations in creating DNA chips to enhance the potential for scientific advances and public health improvement. Achieving this objective has implications for the collection and use of DNA samples from populations in low- and middle-income countries (LMICs). Thus, despite its tremendous opportunities, the dynamic and increasingly global landscape of genomic research commercialization has been accompanied by a variety of ethical challenges and concerns [1-5].

Recent reports of alleged unauthorized use of DNA samples from hundreds of African people to develop a DNA chip [6] have reignited discourse on the meanings, implications, and impacts of commercialization, benefit sharing, and appropriate consent in genomic research. These reports have also amplified attention to protocols and procedures for consenting participants into largescale global projects that are likely to generate commercial resources or products. The term "commercialization" is open to different interpretations, leading to potential divergence in understandings when the term appears in a consent form. In particular cultural contexts, the concept of commercialization may be inseparable from the idea of money changing hands suggesting that samples are bought and sold. This illustrates the important role that perception plays in someone's understanding of reality. At one extreme, the very idea of commercialization may produce a negative reaction, as when it is considered to involve making profits, likely at the expense of others, where the loss may be not only financial but possibly damaging to a group's self-identity. Hence, it may be associated with the concept of exploitation. There are examples of situations where this has occurred historically $[7,8]$. At the other end of the spectrum, commercialization may be a necessary means toward a public good. Drugs and vaccines, for example, require investment in research and clinical trials. Commercialization could be one way of distributing benefits. Questions about fairness in the distribution of benefits remain. In between these 2 ends of the spectrum, there are contested areas over the distribution of benefits [9-11]. The potential for exploitation exists in the area of benefit sharing and reciprocity. For example, commercialization of DNA chips by pharmaceutical companies to produce medicines may result

Translational Science, DNA

Commercialization, and Informed Consent in these products only being available in wealthier countries rather than LMICs. Additionally, investigators who collect samples from donors in LMICs may have concerns about giving them to companies from industrialized nations because they are unsure if they will be able to benefit professionally in this transaction. Scientists from LIMCs may not have the scientific infrastructure or capacity to develop applications from DNA chips.

The Human Heredity and Health in Africa (H3Africa) Initiative, established in 2012, facilitates research into diseases on the African continent and develops infrastructure, resources, training, and ethical guidelines to support a sustainable African research enterprise. Because of the vast amount of genetic diversity in African populations, $\mathrm{H} 3$ Africa provides an unparalleled research resource for the benefit of people in Africa and across the globe. Data sharing is a guiding principle for H3Africa, and the translation of research findings to commercial products and resources is consistent with its mission.

There is a growing literature on applications of informed consent processes for genomic research implemented in African settings [12-21], including establishment of and governance for biobanks [22-29]. The H3Africa Guideline for Informed Consent (https:// h3africa.org/) describes challenges surrounding the implementation of consent for genomic research, highlighting concerns about literacy skills, decisional authority to provide consent, and variability in national policies that may impact implementation of informed consent for genomic research. The H3Africa Guideline for Informed Consent suggests that broad consent, in which potential participants give permission to share stored genetic material with other investigators for future unspecified research, is preferred for genomic research in African settings. While broad consent reduces complexities associated with tiered consent, in which potential participants are offered choices about storing, using, and sharing specimens and data, challenges remain. There are concerns that it may reduce the ability of participants to indicate particular choices, especially in population groups whose autonomy may already be compromised by some form of vulnerability [30-33]. A recent report commissioned by the African Academy of Sciences and the African Union Development Agency suggests that a tiered approach to informed consent may be preferable in African settings [34]. Regardless of whether broad consent or tiered consent approaches are used, clarity and comprehension are key factors for achieving the potential translational benefits of DNA commercialization. 


\section{Methods}

Driven by a commitment to transparency and accountability, the H3Africa Administrative Coordinating Center (https:// h3africa.org/) convened a panel of experts (R.C., P.M., and C.D.M.R.) to review research ethics practices employed in the $\mathrm{H} 3$ Africa Consortium projects and make recommendations for improvements with regard to commercialization. The panel was asked, in consultation with members of the H3Africa Consortium, to review policies for data and biospecimen access and H3Africa consent forms and determine how projects have implemented informed consent procedures for studies involving biobanking and sharing data and/or biospecimens.

The H3Africa Administrative Coordinating Center (https:// h3africa.org/) asked H3Africa investigators to submit informed consent documents for their projects. Eighteen investigators submitted documents for projects involving data sharing and use of genetic information (Table 1). Qualitative analysis was employed to identify language included in consent forms on data sharing and data use.

We developed a Commercialization Typology to frame the findings and recommendations. Communications with Consortium members provided context for the entire project, particularly the interpretation of findings from the consent review process. Careful examination of $\mathrm{H} 3 \mathrm{~A}$ Guidelines and policies pertaining to data and biospecimen access was a critical element of our work (http://biorepository.h3africa.org). Our review of consent forms and other research documents submitted by the subset of 18 investigators for H3Africa projects represents the heart of the report we prepared, "H3Africa Report on Commercialization and Informed Consent," available on H3Africa's website (https://h3africa.org/). Our report focused on ethical questions concerning commercialization of data and/or biospecimens. While there are many legal issues raised by commercialization, these were beyond the scope of our report.

\section{Results}

A total of 39 informed consent documents associated with the subset of $18 \mathrm{H} 3 \mathrm{~A}$ frica projects were reviewed: 27 Adult Consent Forms, 8 Child Assent Forms, and 4 Information Sheets (Table 2). All 18 projects specified that samples would be used in future research. Seven (38.8\%) of the 18 projects suggested that the samples could be used to develop drugs or other products (Table 3 ). In describing future use of samples, 4 (22.2\%) of the 18 projects referred to commercialization (Table 3). The term "commercialization" was not defined in the documents when it was used. Six (33.3\%) of the 18 projects said explicitly that DNA samples would not be sold, and $6(33.3 \%)$ indicated that profits would not be shared with the participants (Table 4).

Analysis of the H3Africa consent documents contributed to our development of a Commercialization Typol-

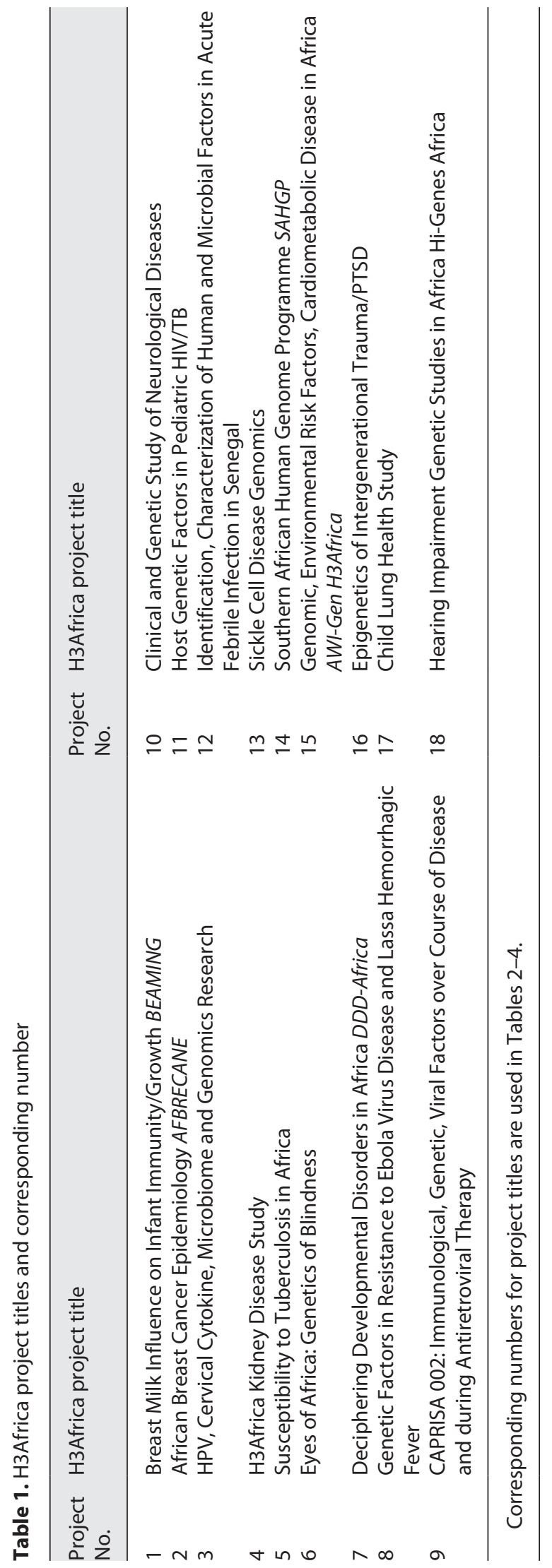

Marshall/Royal/Chadwick 
Table 2. Number and types of H3Africa consent forms reviewed

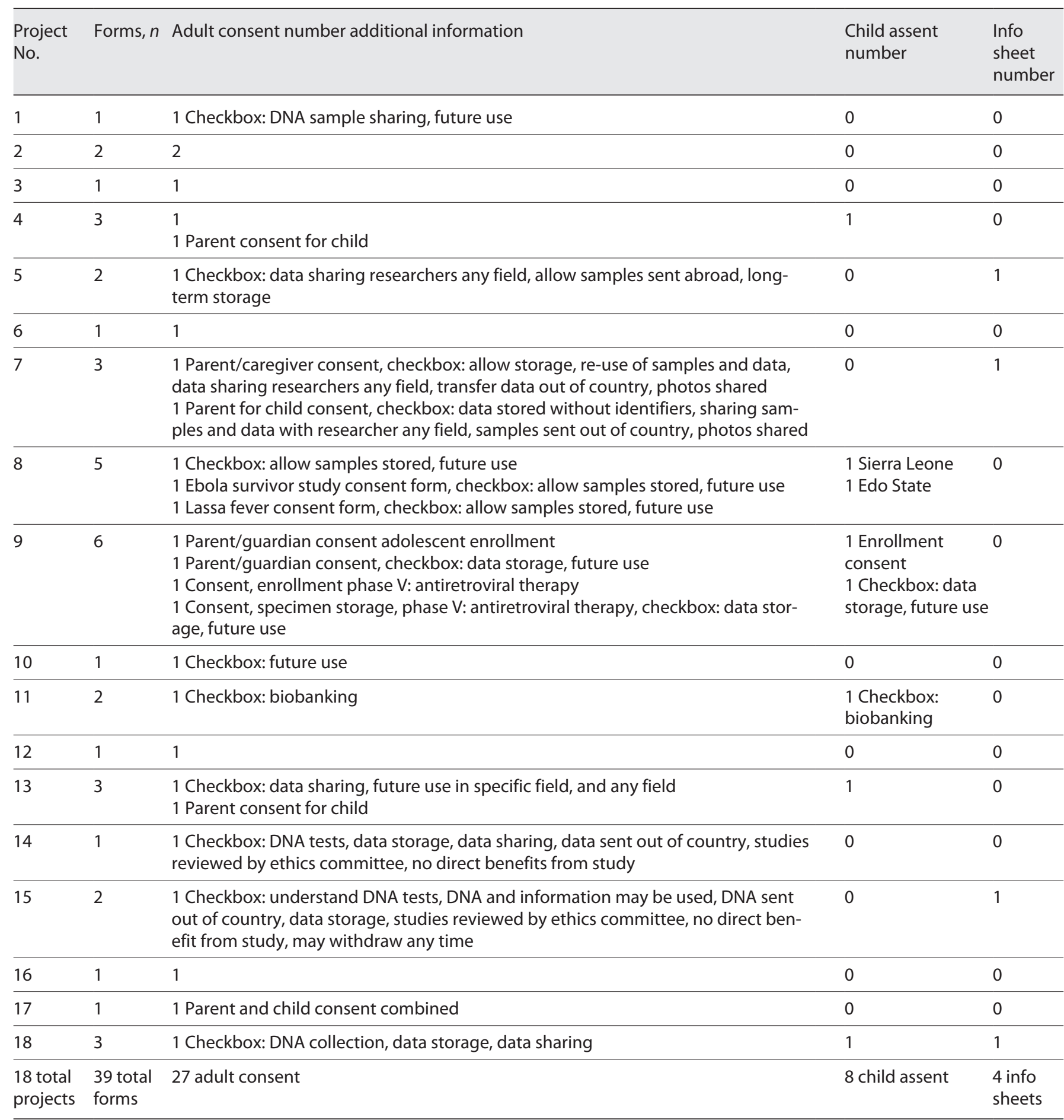

ogy to clarify possible meanings of commercialization and to identify associated issues of concern. An obvious starting point might be that the word "commercialization" conjures up an image of buying and selling. While selling may be a mode of commercialization in the pathways from research to product development, there are others to be considered, such as investment. Moreover, attitudes toward commercialization may depend on 
Table 3. Projects noting future use of DNA for product development or commercialization
Table 4. Projects noting DNA samples will not be sold and donors will not profit

\begin{tabular}{llllll}
\hline Project No. & \multicolumn{2}{l}{ Drug/product development } & & \multicolumn{2}{l}{ Commercialization } \\
\cline { 2 - 3 } \cline { 5 - 6 } & yes, $n(\%)$ & no, $n(\%)$ & & yes, $n(\%)$ & no, $n(\%)$ \\
\hline 1 & $0(0.000)$ & $1(0.056)$ & & $0(0.000)$ & $1(0.056)$ \\
2 & $0(0.000)$ & $1(0.056)$ & & $0(0.000)$ & $1(0.056)$ \\
3 & $0(0.000)$ & $1(0.056)$ & & $1(0.056)$ & $0(0.000)$ \\
4 & $0(0.000)$ & $1(0.056)$ & & $0(0.000)$ & $1(0.056)$ \\
5 & $0(0.000)$ & $1(0.056)$ & & $0(0.000)$ & $1(0.056)$ \\
6 & $1(0.056)$ & $0(0.000)$ & & $1(0.056)$ & $0(0.000)$ \\
7 & $0(0.000)$ & $1(0.056)$ & & $0(0.000)$ & $1(0.056)$ \\
8 & $1(0.056)$ & $0(0.000)$ & & $1(0.056)$ & $0(0.000)$ \\
9 & $1(0.056)$ & $0(0.000)$ & & $0(0.000)$ & $1(0.056)$ \\
10 & $1(0.056)$ & $0(0.000)$ & & $0(0.000)$ & $1(0.056)$ \\
11 & $0(0.000)$ & $1(0.056)$ & & $1(0.056)$ & $0(0.000)$ \\
12 & $1(0.056)$ & $0(0.000)$ & & $0(0.000)$ & $1(0.056)$ \\
13 & $1(0.056)$ & $0(0.000)$ & & $0(0.000)$ & $1(0.056)$ \\
14 & $0(0.000)$ & $1(0.056)$ & & $0(0.000)$ & $1(0.056)$ \\
15 & $0(0.000)$ & $1(0.056)$ & & $0(0.000)$ & $1(0.056)$ \\
16 & $0(0.000)$ & $1(0.056)$ & & $0(0.000)$ & $1(0.056)$ \\
17 & $1(0.056)$ & $0(0.000)$ & $0(0.000)$ & $1(0.056)$ \\
18 & $0(0.000)$ & $1(0.056)$ & $0(0.000)$ & $1(0.056)$ \\
\hline $\mathbf{1 8}$ total projects & $\mathbf{7 ( 0 . 3 8 8 )}$ & $\mathbf{1 1 ( 0 . 6 1 1 )}$ & $\mathbf{4 ( 0 . 2 2 2 )}$ & $\mathbf{1 4 ( 0 . 7 7 7 )}$ \\
\hline
\end{tabular}

\begin{tabular}{|c|c|c|c|c|}
\hline \multirow[t]{2}{*}{ Project No. } & \multicolumn{2}{|c|}{ DNA samples will not be sold } & \multicolumn{2}{|c|}{$\begin{array}{l}\text { Donors will not profit from } \\
\text { product development }\end{array}$} \\
\hline & yes, $n(\%)$ & no, $n(\%)$ & yes, $n(\%)$ & no, $n(\%)$ \\
\hline 1 & $0(0.000)$ & $1(0.056)$ & $0(0.000)$ & $1(0.056)$ \\
\hline 2 & $0(0.000)$ & $1(0.056)$ & $0(0.000)$ & $1(0.056)$ \\
\hline 3 & $0(0.000)$ & $1(0.056)$ & $1(0.056)$ & $0(0.000)$ \\
\hline 4 & $0(0.000)$ & $1(0.056)$ & $0(0.000)$ & $1(0.056)$ \\
\hline 5 & $0(0.000)$ & $1(0.056)$ & $0(0.000)$ & $1(0.056)$ \\
\hline 6 & $1(0.056)$ & $0(0.000)$ & $1(0.056)$ & $0(0.000)$ \\
\hline 7 & $0(0.000)$ & $1(0.056)$ & $0(0.000)$ & $1(0.056)$ \\
\hline 8 & $1(0.056)$ & $0(0.000)$ & $0(0.000)$ & $1(0.056)$ \\
\hline 9 & $0(0.000)$ & $1(0.056)$ & $0(0.000)$ & $1(0.056)$ \\
\hline 10 & $1(0.056)$ & $0(0.000)$ & $1(0.056)$ & $0(0.000)$ \\
\hline 11 & $1(0.056)$ & $0(0.000)$ & $1(0.056)$ & $0(0.000)$ \\
\hline 12 & $0(0.000)$ & $1(0.056)$ & $0(0.000)$ & $1(0.056)$ \\
\hline 13 & $1(0.056)$ & $0(0.000)$ & $1(0.056)$ & $0(0.000)$ \\
\hline 14 & $0(0.006)$ & $1(0.056)$ & $0(0.000)$ & $1(0.056)$ \\
\hline 15 & $0(0.000)$ & $1(0.056)$ & $0(0.000)$ & $1(0.056)$ \\
\hline 16 & $1(0.056)$ & $0(0.000)$ & $0(0.000)$ & $1(0.056)$ \\
\hline 17 & $1(0.056)$ & $0(0.000)$ & $1(0.056)$ & $0(0.000)$ \\
\hline 18 & $0(0.000)$ & $1(0.056)$ & $0(0.000)$ & $1(0.056)$ \\
\hline 18 total projects & $6(0.333)$ & $12(0.666)$ & $6(0.333)$ & $12(0.666)$ \\
\hline
\end{tabular}

what exactly is commercialized: for example, how different bodily tissues (e.g., blood) are regarded as having more or less importance. Also, the identity of the different parties involved, and the balance of power between them, may affect how we regard commercial transactions. Table 5 describes the Commercialization Typology which highlights the meanings and ethics of commercialization. 


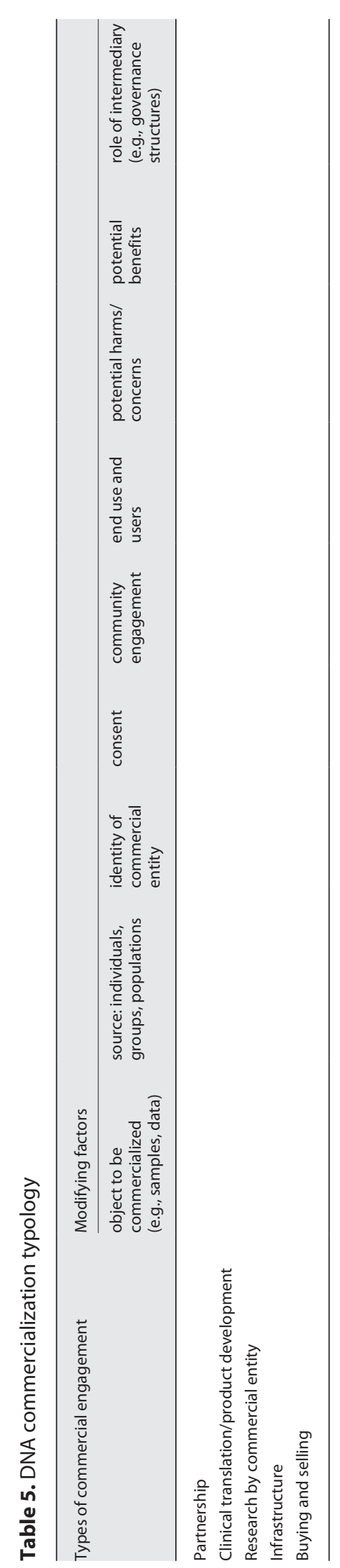

Translational Science, DNA

Commercialization, and Informed Consent
The vertical columns in the typology describe different modes of commercialization. What type of commercial engagement is proposed? A potential monopoly of ownership of the results of research? Or a situation in which a commercial company is offering to invest in infrastructure for research or future health care, for example, by financing laboratories or treatment facilities? A partnership is an arrangement between parties whereby they agree to cooperate to advance their mutual interests, sharing in both responsibilities (e.g., contributing something of value) and benefits. This is achieved by constructing a trust-based agreement "to share the benefits of research in meaningful ways and ensure ... incentives are aligned so that we can succeed together" [35]. A preparatory period of transparency and consultation about what is important to the different parties is a prerequisite.

The horizontal columns illustrate various modifiers of potential commercial engagement. For example, what type of company is involved? Not all companies are thought to have good reputations, whether justifiably or not, in particular cases. Another question concerns consequences in the longer term. Who will the end users be of any resulting product: the source population and/or others? What are potential harms or benefits that may accrue to the source population? Is there a benefit-sharing plan in place? Infrastructure to support scientific translation of DNA samples and data for population health is a theme that cuts across all of these questions in the Commercialization Typology; therefore it was not included as a separate component. Similarly, some themes, such as intellectual property and conflicts of interest, are also relevant across all questions raised in the Commercialization Typology and have not been included as separate items.

Although the typology does not weigh different factors, there are some guiding principles to take into consideration about priorities. First, while this typology could be used in different settings, there is a need to ensure that any instance of commercialization does not conflict with overarching aims (in our case, those of H3Africa). Second, specific consent to commercialize (or not) is widely acknowledged to override other considerations. Difficulties arise when such consent is either silent on commercialization issues, e.g., in legacy collections, or insufficiently clear. These situations will require deliberations and actions relevant to each case. The typology we present thus has implications for the design of consent forms going forward, in terms of the need for specificity, and this point informs our recommendations. 


\section{Conclusion}

The commercialization typology highlights the complex range of meanings associated with "commerce." Rather than a polarity, issues surrounding commercialization fall along a continuum between exploitation and shared benefit. Our analysis of the informed consent documents suggest clarity is needed about sharing genetic samples. Less than half of the 18 projects indicated on consent forms that genetic samples would not be sold, and that participants would not share in the profits from drug or product development. Moreover, only 4 of the 18 projects used the term "commercialization." Our recommendations are as follows:

1. Standardized language for concepts such as selling and profiting in relation to commercialization is needed

2. Consent forms need to be explicit about researchers not selling samples and participants not profiting

3. Investigators should refrain from using the term "commercialization" without specificity

4. Community engagement for studies involving the sharing of biospecimens and/or data should include conversation about commercialization

5. Empirical research is needed on perspectives of diverse stakeholders regarding commercialization

6. A global framework is desirable to guide commercialization processes

\section{Acknowledgments}

We thank the H3Africa Coordinating Center and Principal Investigators for providing the H3Africa materials needed to produce the H3Africa Report on Commercialization and Informed Consent.

\section{Statement of Ethics}

Research was conducted ethically in accordance with the World Medical Association Declaration of Helsinki. Informed consent documents of H3Africa projects were provided by H3Africa leadership. Study approval was not needed for our inquiries because the research was document based and did not involve research interactions with human subjects.

\section{Conflict of Interest Statement}

The authors have no conflicts of interest to declare.

\section{Funding Sources}

Funding was not provided by any source.

\section{Author Contributions}

P. Marshall, C.D.M. Royal, and R. Chadwick contributed to the conceptualization of the manuscript, analysis of H3Africa materials, the development of the Commercialization Typology, and writing.

\section{Data Availability Statement}

Data from the analysis of consent forms are presented in Tables 1-4 in the manuscript. Information on the projects reviewed and our analysis of consent forms is also available in the "H3Africa Report on Commercialization and Informed Consent" on the $\mathrm{Hu}$ man Heredity and Health in Africa (H3Africa) website (https:// h3africa.org/).

\section{References}

1 Caulfield T, Burningham S, Joly Y, Master Z, Shabani M, Borry P, et al. A review of the key issues associated with the commercialization of biobanks. J Law Biosci. 2014;1: 94-11.

2 Haddow G, Laurie G, Cunningham-Burley S, Hunter KG. Tackling community concerns about commercialisation and genetic research: a modest interdisciplinary proposal. Soc Sci Med. 2007;64(2):272-82.

3 Nicol D, Critchley C, McWhirter R, Whitton T. Understanding public reactions to commercialization of biobanks and use of biobank resources. Soc Sci Med. 2016;162:79-87.

4 Evers K, Forsberg J, Hansson M. Commercialization of biobanks. Biopreserv Biobank. 2012;10(1):45-7.
5 Spector-Bagdady K, Krenz CD, Brummel C, Brenne JC, Bradford CR, Shuman AG. "My research is their business, but I'm not their business": patient and clinician perspectives on commercialization of precision oncology data. Oncologist. 2020;25:620-6.

6 Stokstad E. Genetics lab accused of misusing African DNA. Science. 2019;366:555-6.

7 Lunshof JE, Chadwick R. Editorial: genetic and genomic research-changing patterns of accountability. Account Res. 2011;18:121-31.

8 Guglielmi G. Facing up to injustice in genome science. Nature. 2019;568:290-3.

9 Munung NS, de Vries J. Benefit sharing for human genomics research: awareness and expectations of genomics researchers in sub-Saharan africa. Ethics Hum Res. 2020 Nov;42(6):14-20.
10 Staunton C, Adams R, Dove ES, Harriman N, Horn L, Labuschaigne M, et al. Ethical and practical issues to consider in the governance of genomic and human research data and data sharing in South Africa: a meeting report AAS Open Res. 2019 May 22;2:15.

11 Nansumba H, Ssewanyana I, Tai M, Wassenaar $\mathrm{D}$. Role of a regulatory and governance framework in human biological materials and data sharing in National Biobanks: case studies from Biobank integrating platform, Taiwan and the national biorepository, Uganda. Wellcome Open Res. 2020 Sep 1;4:171.

12 Bukini D, Mbekenga C, Nkya S, Purvis L, McCurdy S, Parker M, et al. A qualitative study on aspects of consent for genomic research in communities with low literacy. BMC Med Ethics. 2020;21:48. 
13 Ogunrin O, Woolfall K, Gabbay M, Frith L. Relative solidarity: conceptualising communal participation in genomic research among potential research participants in a developing Sub-Saharan African setting. PLoS One. 2018;13(4):e0195171.

14 Masiye F, Mayosi B, De Vries J. "I passed the test"! Evidence of diagnostic misconception in the recruitment of population controls for an H3Africa genomic study in Cape Town, South Africa. BMC Med Ethics. 2017;18(1): 12.

15 Munung NS, Marshall P, Campbell M, Littler $\mathrm{K}$, Masiye F, Ouwe-Missi-Oukem-Boyer O, et al. Obtaining informed consent for genomics research in Africa: analysis of H3Africa consent documents. J Med Ethics. 2016;42:132-7.

16 Goodman D, Johnson CO, Wenzel L, Bowen $\mathrm{D}$, Condit C, Edwards KL. Consent issues in genetic research: views of research participants. Public Health Genomics. 2016;19(4): $220-8$.

17 Traore K, Bull S, Niare A, Konate S, Thera MA, Kwiatkowski D, et al. Understandings of genomic research in developing countries: a qualitative study of the views of MalariaGEN participants in Mali. BMC Med Ethics. 2015; 16:42.

18 Marshall PA, Adebamowo CA, Adeyemo AA, Ogundiran TO, Strenski T, Zhou J, et al. Voluntary participation and comprehension of informed consent in a genetic epidemiological study of breast cancer in Nigeria. Am J Public Health. 2014;15(1):38.

19 Wright GE, Adeyemo AA, Tiffin N. Informed consent and ethical re-use of African genomic data. Hum Genomics. 2014;8(1):18.
20 Tindana P, Bull S, Amenga-Etego L, De Vries J, Aborigo R, Koram K, et al. Seeking consent to genetic and genomic research in a rural Ghanaian setting: a qualitative study of the MalariaGEN experience. BMC Med Ethics. 2012;13(1): 15 .

21 Ezeome ER, Marshall PA. Informed consent practices in Nigeria. Dev World Bioeth. 2009; 9(3):138-48.

22 Moodley K, Beyer C. Tygerberg Research Ubuntu-inspired community engagement model: integrating community engagement into genomic biobanking. Biopreserv Biobank. 2019;17(6):613-24.

23 Yakubu A, Tindana P, Matimba A, Littler K, Munung NS, E Madden E, et al. Model framework for governance of genomic research and biobanking in Africa - a content description. AAS Open Res. 2018;1:13.

24 de Vries J, Munung SN, Matimba A, McCurdy S, Oukem-Boyer OM, Staunton C, et al. Regulation of genomic and biobanking research in Africa: a content analysis of ethics guidelines, policies and procedures from 22 African countries. BMC Med Ethics. 2018;18: 8.

25 Tindana P, Campbell M, Marshall P, Littler K, Vincent R, Seeley J, et al. Developing the science and methods of community engagement for genomic research and biobanking in Africa. Glob Health Epidemiol Genom. 2017;2: e13.

26 de Vries J, Munung SN, Matimba A, McCurdy S, Ouwe Missi Oukem-Boyer O, Staunton C, et al. Regulation of genomic and biobanking research in Africa: a content anal$y$ sis of ethics guidelines, policies and procedures from 22 African countries. BMC Med Ethics. 2017;18(1):8.
27 Moodley K, Singh S. "It's all about trust": reflections of researchers on the complexity and controversy surrounding biobanking in South Africa. BMC Med Ethics. 2016;17(1): 57.

28 Barchi F, Little MT. National ethics guidance in Sub-Saharan Africa on the collection and use of human biological specimens: a systematic review. BMC Med Ethics. 2016;17(1):64.

29 Staunton C, Moodley K. Challenges in biobank governance in Sub-Saharan Africa. BMC Med Ethics. 2013;14(1):35.

30 Nembaware V, Johnston K, Diallo AA, Kotze MJ, Matimba A, Moodley K, et al. A framework for tiered informed consent for health genomic research in Africa. Nat Genet. 2019; 51:566-71.

31 Tindana P, de Vries J. Broad consent for genomic research and biobanking: perspectives from low- and middle-income countries. Annu Rev Genomics Hum Genet. 2016;17: 375-93.

32 Mikkelsen RB, Gjerris M, Waldemar G, Sandøe P. Broad consent for biobanks is best - provided it is also deep. BMC Med Ethics. 2019;20(1):71.

33 Steinsbekk KS, Kåre Myskja B, Solberg B. Broad consent versus dynamic consent in biobank research: is passive participation an ethical problem? Eur J Hum Genet. 2013;21(9): 897-902.

34 Nordling L. Give African research participants more say in genomic data, say scientists. Nature. 2021;590:542.

35 Farnum A. Variant bio: a new model for genomic research partnerships. 2021 [cited 2021 Sep 23]. Available from: www.variantbio.com. 